\title{
Development of Psychomotor Skills in Dentistry Based on Motor Learning Principles: A Review
}

\author{
Sheeba Khan ${ }^{1}$, Mohammed NK Inamdar ${ }^{2}$, Swapna Munaga ${ }^{3}$, Neha Khare ${ }^{4}$, Mohd Umar Farooq ${ }^{5}$
}

\begin{abstract}
Aim: This review aims to recapitulate the available literature for skill development, instruction, and evaluation of the dental and dental hygiene preclinical students.

Background: The attainment of psychomotor skills is a crucial competence in dental education. The dental profession demands high precision and skill that require the development of cognition, distinctive abilities, and motivation, which influence motor performance. Practical instructions and knowledge for dental instrumentation necessitate the association of knowledge of motor skills with excellent motor skills attainment. Dental trainees need small, unequivocal steps that outline production. Preceding any task, the skill needed for the task should be projected precisely by the learner. Appropriate and detailed feedback from the trainer to the trainee contributes to learning and evolving.

Review results: This review reveals that learning of dexterity accretion should ingress both the aspects of psychomotor skills, that is the motor performance and motor learning, to obtain data that can be used to support skill learning.

Conclusion: To gain a better understanding of the accretion of cognitive content in operative dentistry, and differences in dental performance, more research should focus on factors such as the learning environment, including the type and sequence of learning activities. There is a critical need for staff development for the laboratory tutors who develop positive learning environment and provide students with effective feedback. Clinical significance: This review highlights the importance of preclinical exercises in dentistry and how it enhances the psychomotor skills of students making them better clinicians in future. Reforms are needed in dentistry for improvement in learning atmosphere, proper arrangement of learning activities, and staff development for the laboratory tutors.

Keywords: Grade point average, Motor learning theories, Perceptual aptitude test, Preclinical exercises, Psychomotor skills.

World Journal of Dentistry (2020): 10.5005/jp-journals-10015-1734
\end{abstract}

\section{INTRODUCTION}

Dentistry, like other medical and paramedical professions, requires a high level of clinical skills that necessitates broad usage of cognitive, affective, and psychomotor domains of learning. ${ }^{1}$

The learning and acquisition of psychomotor skills are highly crucial for a successful dental professional. ${ }^{2}$ Dental programs demand high accuracy encompassing irrevocable surgical work. The students need to cultivate these skills during their beginning years of the program before delivering real patient care.

The application of motor skills in dental procedures requires the utilization of knowledge and cognition in coordination with the eye, finger, and hand movements. These movements may involve procedures using a range of instruments while performing carving in the preclinical lab, activating hand scalers in periodontal treatment, preparing a cavity, or crown-cutting procedures. ${ }^{3}$

Moreover, dentistry is a field wherein there are always innovations and inclusions of newer technologies and materials for which the dentist should be continuously developing their motors skills. ${ }^{4}$

Psychomotor abilities can be characterized as those that require the subject to have the ability to synchronize sensorial data and strong motor coordination so as to play out a decided errand. ${ }^{5}$ According to Rose and Christina, these skills are involved in controlling muscles signaled by the brain and motor neural pathways resulting in steadfast movement. ${ }^{6}$

This article aims to understand the learning methods in preclinical activities, followed by a review of how psychomotor skills are acquired and applied for developing a relationship between ability, performance, and motivation.
${ }^{1}$ Department of Restorative Dental Sciences, Division of Endodontics and Operative Dentistry, College of Dentistry and Pharmacy, Buraydah Private Colleges, Buraydah, Qassim, Kingdom of Saudi Arabia

${ }^{2}$ Department of Preventive Dental Sciences, Division of Periodontics, College of Dentistry and Pharmacy, Buraydah Private Colleges, Buraydah, Qassim, Kingdom of Saudi Arabia

${ }^{3}$ Dentora Dental Clinic, Hyderabad, Telangana, India

${ }^{4}$ Department of Periodontics, RKDF Dental College and Research Centre, Bhopal, Madhya Pradesh, India

${ }^{5}$ Department of Public Health Dentistry, Government Dental College and Research Institute, Bengaluru, Karnataka, India

Corresponding Author: Sheeba Khan, Department of Restorative Dental Sciences, Division of Endodontics and Operative Dentistry, College of Dentistry and Pharmacy, Buraydah Private Colleges, Buraydah, Qassim, Kingdom of Saudi Arabia, Phone: +966552249612, e-mail: drsheebakhaninamdar@gmail.com

How to cite this article: Khan S, Inamdar MNK, Munaga S, et al. Development of Psychomotor Skills in Dentistry Based on Motor Learning Principles: A Review. World J Dent 2020;11(3):247-251.

Source of support: Nil

Conflict of interest: None

\section{Learning Methods in Preclinical Activities}

In a dental curriculum, students develop their psychomotor skills by working in preclinical laboratories as a part of the curriculum. 
Because of the multifaceted nature of aptitudes required, novice apprentices invest a lot of energy and time creating and practicing these abilities through their preclinical exercises. Exercises extend from the utilization of customary benchtop tasks, including manikins to high innovation gadgets, e.g., computer-generated virtual reality test systems $\mathrm{s}^{7,8}$ In preclinical exercises, the students are required to use their theoretical knowledge, preparing them to deal with a wide range of case scenarios on simulation to meet similar clinical situations. They also learn to develop spatial abilities and reasoning abilities to gauge their motor skills. Other skills that are refined in preclinical activities are indirect visualization, cavity depth assessment, accessibility, and self-positioning. ${ }^{9}$

With the incredible advancement in the field of simulation, the students have preclinical experience close to reality. The lifelike manikins and simulators place the student in an objective setting similar to the actual patient encounter in the clinic, for example, utilization of indirect vision with the help of a mouth mirror while operating in posterior maxillary teeth and retracting the soft tissues.

The performance of the students is monitored by the faculty and simulators who provide feedback to students concerning the structure and measurements of their cavity preparations. Wierinck et al. reported that computer-based simulation approaches are very promising in dentistry in surgical skill training. ${ }^{8}$ By the opinion of Bradley et al. and Okuda et al., there have been doubts whether these test systems could improve learning abilities in preclinical settings and empower the pupils to apply these aptitudes in patient treatment and care. ${ }^{10-13}$ One of the hindrances with the utilization of test systems is the constrained incorporation of concepts of skill growth and improvement in the plan of learning exercises, which is essential for novice students. Few authors like Quinn et al. still believe that the conventional laboratory method has value in enhancing the interactions with the instructors and aids in acquiring critical feedback. ${ }^{14}$

\section{Motor Performance and Motor Learning Perspectives in the Development of Psychomotor SKILls}

Historians like Mc Geoch, Irion, and Adams provided detailed reviews of motor learning research in the past century. Early experimental investigations of motor learning were concerned with real-world skills and the problems associated with their acquisition, retention, and transfer. Disinterest in motor learning research continued through the end of the century. However, the relevance of motor learning to other disciplines such as health, paramedical field, sports skills, surgical skills, the skill acquisition theories laid up by Adams et al., and schema theory by Schmidt et al. have revitalized motor learning. ${ }^{15,16}$

Motor performance alludes to the unequivocal physical activities or the results of a task. To illustrate, while assessing the performance of motor skills in the field of cavity cutting and preparation, the evaluators mostly focus the final cavity preparation. Accordingly, there is no data about the dental students' aptitudes utilized during the cavity preparation, which thus restrains the kind of response that can be given. Conversely, motor learning alludes to the capacity of an individual to comprehend the procedures and results expected, prompting everlasting changes in their presentation according to Schmidt et al. ${ }^{17}$ Motor learning is the process by which the capability for skilled motor control becomes represented in memory. Motor learning is most often associated with the field directed at understanding the acquisition of skill with practice or experience. ${ }^{16,17}$

Acquiring data from studies and implementing them on skill learning is essential. Presently, according to Tedesco et al., dental education programs mostly evaluate the psychomotor skills concerning outcome-based motor performances, without being assessed for learning processes for psychomotor skills development. ${ }^{18}$

\section{Methods of Evaluation of Performance}

Evaluation of motor performance in various professions been an essential aspect of the curriculum in recent studies. Many instruments are used in various professions such as time, hand movement, final merchandise rating, agendas, and masterclass worldwide appraisals according to Hamstra et al. ${ }^{19}$ Conferring to De Andrés et al. and Heintze et al., in dentistry, motor evaluation, by and large, has been assessed utilizing the final product rating, e.g., scores for cavity preparation, restoration, and ranks for clinical and practical examination. . $^{20}$

In general, instructor valuation methods apply to the awarding of grades. According to Cook and Beckman, the significant point here is assurance of the cogency and consistency of assessment instruments used for practical presentations, which has an impact on analyzing the results in such studies. ${ }^{21}$ In dentistry, assessment instruments with validity and reliability are inadequate in general in the view of Gillet et al. and De Andrés et al. ${ }^{5,22}$

Beckman et al. showed that five foundations of cogency confirmation have been described with reference to medical education. These foundations include the content, feedback process, internal structure, affiliation with different factors, and outcomes. According to them, cogency is centered more around providing proof to help important interpretations as opposed to concentrating on the property of the evaluation tool itself. All things considered, past investigations have not generously tended to these perspectives, and this will hamper the effectiveness of the reported outcomes. ${ }^{23}$

Haynes et al. reported that this might end in overrepresentation or underrepresentation of some of the features of the hypothesis of interest, such as the manual skills of the students. Due to limitations in previous studies conducted on dental training, in the domain of psychomotor expertise development and inadequate utilization of skill learning theories, the emphasis was on only one perception for the research on psychomotor skills, that is, motor skills and inadequate exploration of the cogency of tool used. ${ }^{24}$

Researchers suggest several possible methods to evaluate the performance of a learner. They are classified as post-acquisition tests, retention tests, and transfer tests. Post-acquisition tests improve learning, and they measure performance immediately after the teaching and practicing of a new skill. These are valid methods to measure a change in performance. Still, the drawback is because of the immediacy of testing, caution in interpreting the performance must be exercised, as it is the reflection of a temporary situation. Its association should not be with concomitant enduring change related to learning.

Retention test measures the performance during which a rest period is present between the last practiced skill and the retention test. The rest period is usually a few hours or days. This rest period eliminates the temporary effects of the practiced skill and measures learning that indicates the permanent changes. With transfer tests, the ability of the learner to adapt the newly learned procedural 
skill to a different situation is tested, for instance, practicing like tasks under a time constraint in an innovative setting regularly at the time-point interval to skill acquisition phase. The reason for transfer tests is that the adaptability of a learner to a variety of circumstances increases with the degree of learning. ${ }^{25}$ This indicates that in a state where there is a failure in learning but momentary progress in performance on a post-acquisition test, a person might either have the minimal skill or completely unable to adjust to the technique in a novel circumstance.

On the contrary, a skilled person who has acquired genuine learning will be able to adapt the procedural skills to new demands.

\section{Relationship between Ability, Performance, and Motivation}

The field of dentistry requires acquiring psychomotor skills as a critical competence, and it is seen that an individual's innate abilities greatly influence motor performance and motivation. ${ }^{4}$ Innate ability is the necessary aptitude associated with an individual while performing a task. ${ }^{17}$

As indicated by the hypothesis of skill acquisition, there are three critical abilities needed in various phases of dexterity accretion. ${ }^{26}$ First, the cognitive phase is required to comprehend the strategies and methods related to a specific assignment. Besides, the associative stage, perceptual speed capacity is needed to find the best method to accomplish the task. ${ }^{27}$ Third, in the autonomous stage, performance is overwhelmed by a student's psychomotor ability, with less dependence on their cognitive ability. ${ }^{28}$

Keehner et al. proved that the relationship between ability and motor performances has been reported in many studies in various fields of surgery, indicating the close association between cognition and performance in surgical simulation, proposing that for the acquisition of particular skills, it is essential to have a specific ability. ${ }^{29}$ This also implies those dental graduates who have a high level of propensity that is required in dentistry ought to likewise exhibit a significant level of dental psychomotor performance. Based on the scores obtained in the ability tests like grade point average (GPA), visual-spatial ability test, and perceptual aptitude test (PAT) have been used in predicting performance in dental preclinical operative sessions. ${ }^{17}$ According to Boyle and Santelli, ${ }^{30}$ Walcott et al., ${ }^{31}$ and Gansky et al., ${ }^{32}$ it has been noticed in dentistry that college GPA is not related to performance in preclinical courses, and grades are not considered to straightforwardly mirror the learning parameters required in dexterity accretion. Grade point average denotes a broad measurement of an aptitude of obtaining basic knowledge, suggesting to test cognitive ability concerning obtaining evidence regarding which factors are necessary for the achievement of psychomotor skills in dentistry.

Several studies have scrutinized the predictive value of a visual-spatial ability test, namely, the PAT, concerning dental performance in preclinical operative courses conferring to Gansky et al., ${ }^{32}$ Kramer, $^{33}$ and Oudshoorn. ${ }^{34}$ In any case, the outcomes have been conflicting. A few investigations have indicated that the estimations of relapse coefficients of absolute PAT scores in anticipating dental performance are low. A positive relationship was found between the outcomes in a preclinical course and grades on a spatial capacity test. In this study, the spatial capacity was estimated by requesting that examinees envision a three-dimensional article when given different two-dimensional perspectives. The absence of steady outcomes in past investigations may be because of an absence of clear homogenization of theory in the selection of ability tests. ${ }^{20,32}$ The research has concentrated on recognizing the viability of different cognitive and manual adeptness tests in predicting dental performance. ${ }^{35,36}$ There are no particular test scores to gauge success in dental programs, since studies performed earlier delivered a wide range of results with no conclusions. These inconsistencies are related to the partial, unambiguous use of the perilous theories, e.g., skill acquisition theory, to the study designs used. It is proved that while cognitive capacity, explicitly the visualspatial ability, related to the performance by dental understudies on a new mind-boggling surgical task, there was no relationship between visual-spatial ability and operational execution for advanced students and specialists. It was suggested that ability and performance are prejudiced by practice and experience. ${ }^{37}$

Another study reported the correlation of innate ability with performance differences in initial phases of learning. However, they concluded that with repeated performance of the same task, the differences in performance result were reduced. ${ }^{29}$

Motivation is the vital aspect of learning motor skills. ${ }^{38}$ It is related to consequent learning results, particularly when another learning model is familiarized to the students. ${ }^{39}$ Motivation is the internal effort allocated to tasks, and it influences the ability and performance and thereby increasing skill acquisition. ${ }^{40}$ The motivation of an individual has a significant influence on motor performance.

According to a few experts like Langan-Fox et al., individuals showing high motivation are likely to attain a high level of performance. ${ }^{41}$ According to the motivation theory, abstract psychological exertion is a powerful construct affected by different components, including goal orientation, goal-setting, and selfregulatory processes. ${ }^{42-44}$ The goal-setting stage includes goals and decisions that will be given to different undertakings, and this is affected by factors, for example, task intricacy and self-viability. Among people who set targets for themselves, those with great self-efficiency are more probable to fix higher targets than those with less self-efficiency. ${ }^{45}$ Self-regulatory processes enable people to contrast real performance and the ideal objective, bringing about an alteration in the subjective effort due to the amount of motivation provided to accomplish the ideal objective according to Yeo et al. ${ }^{44}$

Motivational determinants have been accounted for abilityperformance interactions, with less motivation bringing about low degrees of performance among people with low- and high-performance ability. ${ }^{42}$ In disparity, with high motivation, unpredictability in ability tends to decree performance. Despite the significant role of impetus and effort in accomplishing highquality motor performance in dentistry, the subject related to motor performance or motor learning has not been explored adequately. Thus, it can be advised that future research should focus on important facets such as the learning atmosphere, which includes the type and arrangement of learning activities. There is a perilous need of staff development for the laboratory tutors who develop positive learning environment and provide students with effective feedback to enhance the process of learning.

\section{CONCLUSION}

This review reveals that research on skill acquisition ought to evaluate both the aspects of psychomotor skills, that is, the motor performance and motor learning, to get data that can be utilized to help skill learning. Be that as it may, dental education research, for the most part, investigates psychomotor aptitudes as far as motor 
performance outcomes results, with a constrained evaluation of the learning processes for psychomotor skills improvement.

The majority of studies have inspected the impact of cognitive ability and psychomotor ability on cavity preparation exercises, with weak positive associations for the association between perceptual speed ability and performance in operative dentistry. It looks like up till now, ability tests in dentistry were used without first authenticating them based on theory. To get more knowledge about the attainment of psychomotor skills in operative dentistry, and the differences in dental tasks performance, we advise that research should focus on aspects such as improvement in learning atmosphere, including the type and arrangement of learning activities and staff development for the laboratory tutors.

\section{References}

1. Orlich DC, Harder RJ, Callahan RC, et al. Teaching Strategies: A Guide to Effective Instruction. Boston, Wadsworth (ed): Cengage Learning; 2009.

2. The Royal Australian College of General Practitioners: Procedural Skills. In: The RACGP Curriculum for Australian General Practice 2011. Victoria, Australia: The Royal Australian College of General Practitioners. The Royal Australian College of General Practitioners, 2011.

3. Afify AR, Zawawi KH, Othman HI, et al. Correlation of psychomotor skills and didactic performance among dental students in Saudi Arabia. Adv Med Educ Pract 2013;4:223-226. DOI: 10.2147/AMEP. S53319.

4. Suksudaj N, Townsend GC, Kaidonis J, et al. Acquiring psychomotor skills in operative dentistry: do innate ability and motivation matter? Eur J Dent Educ 2012;16(1):e187-e194. DOI: 10.1111/j.16000579.2011.00696.x.

5. De Andrés AG, Sánchez E, Hidalgo JJ, et al. Appraisal of psychomotor skills of dental students at university complutense of Madrid. Eur J Dent Educ 2004;8(1):24-30. DOI: 10.1111/j.1600-0579.2004.00296.x.

6. Rose DJ, Christina RW. A multilevel approach to the study of motor control and learning. San Francisco: Pearson/Benjamin Cummings (ed): Pearson; 2006.

7. Wierinck E, Puttemans V, Swinnen S, et al. Effect of augmented visual feedback from a virtual reality simulation system on manual dexterity training. Eur J Dent Educ 2005;9(1):10-16. DOI: 10.1111/j.16000579.2004.00351.x.

8. Wierinck E, Puttemans V, Van Steenberghe D. Effect of tutorial input in addition to augmented feedback on manual dexterity training and its retention. Eur J Dent Educ 2006;10(1):24-31. DOI: 10.1111/j.16000579.2006.00392.x.

9. Hegarty $M$, Keehner $M$, Khooshabeh $P$, et al. How spatial abilities enhance, and are enhanced by, dental education. Learn Individ Differen 2009;19(1):61-70. DOI: 10.1016/j.lindif.2008.04.006.

10. Wong JA, Matsumoto ED. Primer: cognitive motor learning for teaching surgical skill-how are surgical skills taught and assessed? Nat Clin Pract Urol 2008;5(1):47-54. DOI: 10.1038/ncpuro0991.

11. Bradley P, Bligh J. Clinical skills centers: where are we going? Med Educ 2005;39(7):649-650. DOI: 10.1111/j.1365-2929.2005.02189.x.

12. Okuda Y, Bryson EO, DeMaria JrS, et al. The utility of simulation in medical education: what is the evidence? Mt Sinai J Med 2009;76(4):330-343. DOI: 10.1002/msj.20127.

13. Quinn F, Keogh P, McDonald A, et al. A study comparing the effectiveness of conventional training and virtual reality simulation in the skills acquisition of junior dental students. Eur J Dent Educ 2003;7(4):164-169. DOI: 10.1034/j.1600-0579.2003.00309.x.

14. Quinn F, Keogh P, McDonald A, et al. A pilot study comparing the effectiveness of conventional training and virtual reality simulation in the skills acquisition of junior dental students. Eur J Dent Educ 2003;7(1):13-19. DOI: 10.1034/j.1600-0579.2003.00264.x.
15. Adams JA. A closed-loop theory of motor learning. Journal of motor behaviour 1971;3(2):111-150. DOI: 10.1080/00222895.1971.10734898.

16. Schmidt RA. A schema theory of discrete motor skill learning. Psychol Rev 1975;82(4):225. DOI: 10.1037/h0076770.

17. Schmidt RA, Lee T. Motor control and learning: A Behavioural emphasis. 4th ed., Champaign, Illinois: Human Kinetics; 2005.

18. Tedesco LA. Issues in dental curriculum development and change. J Dent Educ 1995;59(1):97-147. DOI: 10.1002/j.00220337.1995.59.1.tb02922.x.

19. Hamstra SJ. Predicting the technical competence of surgical residents. Clin Orthopaed Relat Res 2006;449:62-66. DOI: 10.1097/01. blo.0000224060.55237.c8.

20. Heintze U, Radeborg K, Bengtsson H, et al. Assessment and evaluation of individual prerequisites for dental education. Eur J Dent Educ 2004;8(4):152-160. DOI: 10.1111/j.1600-0579.2004.00345.x.

21. Cook DA, Beckman TJ. Current concepts in validity and reliability for psychometric instruments: theory and application. Am J Med 2006;119(2):166-e7. DOI: 10.1016/j.amjmed.2005.10.036.

22. Gillet $D$, Quinton $A$, Jeannel $A$. Is there a link between writing ability, drawing aptitude and manual skills of dental students? Eur J Dent Educ 2002;6(2):69-73. DOI: 10.1034/j.1600-0579.2002.60205.x.

23. Beckman TJ, Cook DA, Mandrekar JN. What is the validity evidence for assessments of clinical teaching? J Gen Intern Med 2005;20(12): 1159-1164. DOI: 10.1111/j.1525-1497.2005.0258.x.

24. Haynes SN, Richard D, Kubany ES. Content validity in psychological assessment: a functional approach to concepts and methods. Psychol Assess 1995;7(3):238. DOI: 10.1037/1040-3590.7.3.238.

25. Magill RA. Motor learning and control: concepts and applications 9th ed., New York: McGraw-Hill. McGraw-Hill Education; 2010.

26. Ackerman PL, Cianciolo AT. Cognitive, perceptual-speed, and psychomotor determinants of individual differences during skill acquisition. J Exp Psychol Appl 2000;6(4):259. DOI: 10.1037//1076898x.6.4.259.

27. Fitts PM, Posner MI. Human Performance-Basic concepts in psychology series. Brooks/Cole Publishing Company, the University of Michigan; 1967.

28. Ackerman PL. Determinants of individual differences during skill acquisition: cognitive abilities and information processing. $J$ Experiment Psychol: Gen 1988;117(3):288-318. DOI: 10.1037/00963445.117.3.288

29. Keehner M, Lippa Y, Montello DR, et al. Learning a spatial skill for surgery: how the contributions of abilities change with practice. Appl Cogn Psychol 2006;20(4):487-503. DOI: 10.1002/acp.1198.

30. Boyle AM, Santelli JC. Assessing psychomotor skills: the role of the crawford small parts dexterity test as a screening instrument. J Dent Educ 1986;50(3):176-179. DOI: 10.1002/j.00220337.1986.50.3.tb01981.x.

31. Walcott AM, Knight GW, Charlick RE. Waxing tests as predictors of students' performance in preclinical dentistry. J Dent Educ 1986;50(12):716-721. DOI: 10.1002/j.0022-0337.1986.50.12.tb02065.x.

32. Gansky SA, Pritchard $H$, Kahl E, et al. Reliability and validity of a manual dexterity test to predict preclinical grades. J Dent Educ 2004;68(9):985-994. DOI: 10.1002/j.0022-0337.2004.68.9.tb03848.x.

33. Kramer G. Predictive validity of the dental admission test. J Dent Educ 1986;50(9):526-531. DOI: 10.1002/j.0022-0337.1986.50.9.tb02035.x.

34. Oudshoorn W. The utility of canadian DAT perceptual ability and carving dexterity scores as predictors of psychomotor performance in first-year operative dentistry. J Dent Educ 2003;67(11):1201-1208. DOI: 10.1002/j.0022-0337.2003.67.11.tb03711.x.

35. Lundergan WP, Soderstrom EJ, Chambers DW. Tweezer dexterity aptitude of dental students. J Dent Educ 2007;71(8):1090-1097. DOI: 10.1002/j.0022-0337.2007.71.8.tb04375.x.

36. Giuliani M, Lajolo C, Clemente L, et al. Is manual dexterity essential in the selection of dental students? Br Dent J 2007;203(3):149. DOI: 10.1038/bdj.2007.688.

37. Wanzel KR, Hamstra SJ, Caminiti MF, et al. Visual-spatial ability correlates with efficiency of hand motion and successful surgical 
performance. Surgery 2003;134(5):750-757. DOI: 10.1016/s00396060(03)00248-4.

38. Yarrow K, Brown P, Krakauer JW. Inside the brain of an elite athlete: the neural processes that support high achievement in sports. Nat Rev Neurosci 2009;10(8):585-596. DOI: 10.1038/ nrn2672.

39. Friedl $\mathrm{R}$, Höppler $\mathrm{H}$, Scholz $\mathrm{W}$, et al. Multimedia driven teaching significantly improves students' performance during heart operations when compared to a print medium: a prospective, randomised trial. Thorac Cardiovasc Surg 2005;53(S01):116. DOI: 10.1055/s-2005-862059.

40. Yeo G, Neal A. A multilevel analysis of effort, practice, and performance: effects of ability, conscientiousness, and goal orientation. J Appl Psychol 2004;89(2):231-247. DOI: 10.1037/00219010.89.2.231.
41. Langan-Fox J, Armstrong $\mathrm{K}$, Balvin $\mathrm{N}$, et al. Process in skill acquisition: motivation, interruptions, memory, affective states, and metacognition. Aust Psychol 2002;37(2):104-117. DOI: 10.1080/00050060210001706746.

42. Kanfer R, Ackerman PL. Motivation and cognitive abilities: an integrative/aptitude treatment interaction approach to skill acquisition. J Appl Psychol 1989;74(4):657-690. DOI: 10.1037/00219010.74.4.657.

43. Grant $\mathrm{H}$, Dweck CS. Clarifying achievement goals and their impact J Pers Soc Psychol 2003;85(3):541. DOI: 10.1037/0022-3514.85.3.541.

44. Yeo G, Neal A. Subjective cognitive effort: a model of states, traits, and time. J Appl Psychol 2008;93(3):617. DOI: 10.1037/0021-9010.93.3.617.

45. Locke EA, Latham GP. Building a practically useful theory of goal setting and task motivation: a 35-year odyssey. Am Psychol 2002;57(9):705-717. DOI: 10.1037/0003-066X.57.9.705. 